\title{
The value of serum Krebs von den lungen- 6 as a diagnostic marker in connective tissue disease associated with interstitial lung disease
}

\author{
Hua Ma ${ }^{1+}$, Junhui $\mathrm{Lu}^{2+}$, Yuanyuan Song ${ }^{1}$, Huixuan Wang ${ }^{1}$ and Songlou Yin ${ }^{1 *}$
}

\begin{abstract}
Objectives: The purpose of this study was to evaluate the value of serum krebs von den lungen-6 (KL-6) level as a diagnostic indicator for connective tissue disease associated with interstitial lung disease (CTD-ILD).

Methods: One hundred fifty five patients with newly diagnosed CTD in our hospital were enrolled and divided into two groups by their ILD manifestations, the CTD-ILD group and the CTD group. In parallel, 61 patients with pulmonary infection and 60 cases of healthy subjects were also enrolled into the study. The difference of serum KL6 level among the four groups were compared. In CTD-ILD group, carbon monoxide diffusing capacity (DLCo) and high-resolution computed tomography (HRCT) of lung were also tested. The serum KL-6 level of 32 patients from the CTD-ILD group who received cyclophosphamide (CTX) pulse therapy were sampled and measured, by enzyme linked immunosorbent assay (ELISA), at three time points: before treatment, 3 months after treatment and 6 months after treatment.

Results: The serum KL-6 level in the CTD-ILD group (1004.9 (676.41738.1) IU/ml) is significantly higher than three other groups $\left(X^{2}=72.29, P<0.001\right)$. In the CTD-ILD group the level of serum $\mathrm{KL}-6$ was positively correlated with disease severity on HRCT ( $r=0.75, P<0.001)$, while was negatively correlated with DLCo $(r=-0.50, P<0.001)$. In 32 patients who received CTX pulse therapy, the level of serum KL- 6 was gradually decreased in 20 cases whose lesions were absorbed within 6 months $(F=13.67, P<0.001)$, whereas it remained unchanged in the rest of 12 patients $(Z=-1.328, P=0.198)$.
\end{abstract}

Conclusions: Serum KL-6 level can potentially serve as a diagnostic marker for CTD-ILD and be utilized to evaluate the effectiveness of CTX pulse therapy.

Keywords: Connective tissue disease, Interstitial lung disease, Connective tissue disease associated with interstitial lung disease, Krebs von den lungen-6

\section{Introduction}

The connective tissue diseases (CTD) are a collective series of immune-mediated pathologies and systemic disorders affecting multiple connective tissues, including chronic inflammation of blood vessels [1]. The lung is rich in blood vessels, collagen and other connective tissues, and play

\footnotetext{
* Correspondence: yinsonglou@163.com

${ }^{+}$Hua Ma and Junhui Lu contributed equally to this work.

'Department of Rheumatology and Immunology, Affiliated Hospital of

Xuzhou Medical University, No. 99 Huaihai West Road, Xuzhou 221002, China

Full list of author information is available at the end of the article
}

important functions in immune, endocrine and metabolic regulations. Therefore, it often becomes the first affected organ of CTD. The ILD is a common complication of CTD and a key risk factor of mortality, which is often diagnosed at an advanced stage. Typically, the onset of ILD is insidious, with only subtle clinical symptoms $[2,3]$.

Currently, pulmonary function test (PFT) and highresolution computed tomography (HRCT) are important diagnostic tools for the assessment of severity of CTDILD [4]. However, HRCT may occasionally cause lung damage, even though mostly rare [5]. As the pathological

(c) The Author(s). 2020 Open Access This article is distributed under the terms of the Creative Commons Attribution 4.0 International License (http://creativecommons.org/licenses/by/4.0/), which permits unrestricted use, distribution, and reproduction in any medium, provided you give appropriate credit to the original author(s) and the source, provide a link to the Creative Commons license, and indicate if changes were made. The Creative Commons Public Domain Dedication waiver (http://creativecommons.org/publicdomain/zero/1.0/) applies to the data made available in this article, unless otherwise stated. 
basis of ILD presents as diffuse alveolar inflammation and pulmonary interstitial fibrosis, the main pathophysiological process is resulted from the injuries and regeneration of alveolar type II epithelial cells [6]. In recent years, many studies suggested that a variety of cytokines associated with alveolar injuries may be useful for the diagnosis of CTDILD and may provide some valuable information for disease prognosis [7].

The Krebs von den Lungen-6 (KL-6) is a mucin-like glycoprotein mainly expressed on the type II alveolar epithelial cell surface [8]. The expression of KL-6 is significantly increased when the alveolar epithelium sustains injuries, and the KL- 6 can be secreted into the bloodstream through the damaged alveolar basement membrane [9]. Thus, elevated serum KL-6 levels may indicate the onset of CTD in patients with ILD and may be used to predict prognosis $[10,11]$. However, other studies showed that KL-6 was a poor prognostic factor for systemic sclerosis (SSc)ILD $[12,13]$. Furthermore, the efficacy of KL-6 to assess the therapeutic effect remains understudied. The main goal of our study was not only to assess if the serum KL-6 level can be included into the clinical practice as a reliable diagnostic indicator for CTD-ILD patients, but also to evaluate possibility to use the value of KL-6 to evaluate the efficacy of CTX treatment on CTD-ILD patients.

\section{Methods}

\section{Patient recruitment}

A total of 155 patients with newly diagnosed CTD from January 2016 to June 2016 in the Affiliated Hospital of Xuzhou Medical University were recruited into this study and were divided into two groups according to their ILD manifestations. All patients were eligible for classification/diagnosis criteria of the corresponding disease. Sixty one cases of pulmonary infection, 60 cases of healthy subjects (who only underwent physical exams) were collected in the same period.

\section{Inclusion criteria}

Patients were diagnosed as CTD-ILD according to the imaging changes based on HRCT: mesh shadows, solid shadows, cellular shadows, ground glass shadows, and nodular shadows $[13,14]$.

\section{Exclusion criteria}

1. With other lung diseases such as tuberculosis, chronic obstructive pulmonary disease and pulmonary infection; 2. Other causes of pulmonary interstitial fibrosis, such as pneumoconiosis, radioactive pneumonia; 3 . Severe organ dysfunction such as heart failure, renal failure, pulmonary hypertension; 4. Patients with malignant tumor; 5. Pregnant and lactating women.

\section{CTX pulse therapy}

The efficacy of the CTX pulse therapy were determined by the following criteria [15]: [1] Invalid: dry cough or wheezing symptoms deteriorate; vital capacity (VC) or DLCo decreased more than 10\% compared with baseline; progression of lung lesion range based on HRCT score [2]. Effective or stable: does not meet any of the above.

\section{Serum KL-6 measurements}

Peripheral fasting blood samples were collected at early morning. The separation of the serum was performed at $3000 \mathrm{rpm}$ for $15 \mathrm{~min}$, and stored at $-80^{\circ} \mathrm{C}$. The serum KL-6 levels were detected by ELISA (Shanghai sailing Biological Technology Co. Ltd). Each measurement value for standard antigen and serum was an average value from two tested samples. In CTD-ILD group, 32 out of total 84 patients were treated with CTX pulse therapy. The assessment of serum KL-6 levels of these 32 patients at three time points, which were: before treatment, 3 months after treatment and 6 months after treatment.

\section{Pulmonary function tests}

In parallel to the serum KL-6 level measurement, HRCT and PFT were performed on the 67 CTD-ILD patients.

The HRCT score: take the aorta arch margin, carina, 1 $\mathrm{cm}$ above the diaphragm, respectively, calculate the three layers of fibrosis accounted for the percentage of the corresponding lung field area. The sum of the scores from three layers is the HRCT score (Table 1). All HRCT images were analyzed by two thoracic radiologists.

\section{Statistical analysis}

The comparison between the two groups of measurement data used Student's $t$-test in the normal distribution, Wilcoxon two sample test when the normal distribution was not used, and the normality in the three groups and above were analyzed by one-way ANOVA. The Kruskal-Wallis test was used for normality, and the SNK method was used after the comparison. KL-6

\begin{tabular}{ll} 
Table 1 HRCT scores & \\
\hline Score & Involving the range (\%) \\
\hline 0 & Normal \\
1 & $1-25$ \\
2 & $26-50$ \\
3 & $51-75$ \\
4 & $>75$ \\
\hline
\end{tabular}

HRCT score: take the aorta arch margin, carina, $1 \mathrm{~cm}$ above the diaphragm, respectively, calculate the three layers of fibrosis accounted for the percentage of the corresponding lung field area, 0 points: normal; 1 points: involving the range of $1-25 \% ; 2$ points: involving the range of $26-50 \% ; 3$ points: involving the range of $51-75 \%$; 4 points: no more than $1 \%$ Involving a range of more than $75 \%$ 
Table 2 The age and gender of each patient group

\begin{tabular}{lllll}
\hline Characteristics & CTD-ILD $n=84$ & CTD $n=71$ & Pulmonary infection $n=61$ & Healty controls $n=60$ \\
\hline Gender, $\mathrm{n}(\%)$ & & & $\mathrm{p}$ \\
$\quad$ Female & $64(76.19)$ & $56(78.87)$ & $40(65.57)$ & $44(73.33)$ \\
$\quad$ Male & $20(23.81)$ & $15(21.13)$ & $21(34.43)$ & $16(26.67)$ \\
Age (years), mean \pm SD & $51.2 \pm 13.75$ & $53.8 \pm 11.58$ & $54.6 \pm 12.89$ & $52.9 \pm 15.67$ \\
\hline
\end{tabular}

comparisons before and after treatment were performed using paired $t$-test or signed rank sum test. The count data was compared between the two groups using the chi-square test or the Fisher exact probability method. Logistic multivariate regression analysis was used to analyze the risk factors for ILD, and correlations between KL-6, HRCT, and DLCo were analyzed using Pearson correlation and Spearman correlation coefficient. The ROC curve of the ILD occurrence for each indicator is plotted, and the cutoff value is taken when the Youden index is the largest. Statistical analysis was performed using SAS
9.3. Use a two-sided test. The difference was considered statistically significant at $P<0.05$.

\section{Results}

General information on study subjects

The patients enrolled included 204 females (73.9\%) and 72 males $(26.1 \%)$ aged average $53.13 \pm 11.19$ years old (from 14- to 89- year-old) (Table 2). From the enrolled CTD patients, 31 patients had rheumatoid arthritis (20.0\%), 24 patients had Sjögren's syndrome (15.48\%), 29 patients had systemic lupus erythematosus (18.06\%), 25

Table 3 Basic characteristics of patients in each of the four groups

\begin{tabular}{|c|c|c|c|}
\hline Characteristics & CTD-ILD, n = 84 & CTD, n = 71 & $\mathrm{p}$ \\
\hline RA,n(\%) & $17(20.24)$ & $14(19.72)$ & 0.936 \\
\hline SS,n(\%) & $12(14.29)$ & $12(16.90)$ & 0.654 \\
\hline SLE,n(\%) & $13(15.48)$ & $16(22.54)$ & 0.262 \\
\hline$\| \mathrm{M}, \mathrm{n}(\%)$ & $14(16.67)$ & $11(15.49)$ & 0.843 \\
\hline SSc,n(\%) & $17(20.24)$ & 9 (12.68) & 0.209 \\
\hline MCTD,n(\%) & $4(4.76)$ & $3(4.23)$ & 1.000 \\
\hline Vasculitis,n(\%) & $5(5.95)$ & $5(7.04)$ & 1.000 \\
\hline OS,n(\%) & $2(2.38)$ & $1(1.41)$ & 1.000 \\
\hline Rash,n(\%) & $14(16.67)$ & 19 (26.76) & 0.126 \\
\hline $\begin{array}{l}\text { Raynaud's } \\
\text { phenomenon,n(\%) }\end{array}$ & $38(45.24)$ & $4(5.63)$ & $<0.001$ \\
\hline Arthritis,n(\%) & $32(38.10)$ & $39(54.93)$ & 0.036 \\
\hline Fever,n(\%)n) & $13(15.48)$ & $13(18.31)$ & 0.638 \\
\hline ANA,n(\%) & $66(78.57$ & $43(60.56)$ & 0.014 \\
\hline $\mathrm{RF}, \mathrm{n}(\%)$ & $38(45.24)$ & $37(52.11)$ & 0.393 \\
\hline ESR $(\mathrm{mm} / \mathrm{H})$, median (IQR) & $40(21,70)$ & $42(21,60)$ & 0.994 \\
\hline CRP (mg/L), median (IQR) & $4.77(2.28,18)$ & $8.31(2.52,31.8$ & 0.143 \\
\hline LDH(U/L), median (IQR) & $235(185,333)$ & $202(169,268)$ & 0.039 \\
\hline $\operatorname{lgG}(\mathrm{g} / \mathrm{L})$, median (IQR) & $17.35(15.05,21.7)$ & $16.1(12.6,20.1)$ & 0.098 \\
\hline C3(g/L), median (IQR) & $0.93(0.8,1.1)$ & $0.93(0.61,1.2)$ & 0.849 \\
\hline C4(g/L), median (IQR) & $0.18(0.14,0.23)$ & $0.19(0.12,0.27)$ & 0.763 \\
\hline $\mathrm{WBC}\left(\mathrm{m} \times 10^{9} / \mathrm{L}\right)$, median $(\mathrm{IQR})$ & $5.8(4.4,9.1)$ & $6.9(4.1,8.6)$ & 0.994 \\
\hline $\mathrm{N}\left(\times 10^{9} / \mathrm{L}\right)$, median $(\mathrm{IQR})$ & $3.58(2.53,6.4)$ & $4.03(2.55,5.91)$ & 0.986 \\
\hline $\mathrm{Hb}(\mathrm{g} / \mathrm{L})$, median (IQR) & $119.5(110,135)$ & $117(103,128)$ & 0.115 \\
\hline $\operatorname{PLT}\left(\times 10^{9} / \mathrm{L}\right)$, median (IQR) & $224(169.5299)$ & $239(155,305)$ & 0.839 \\
\hline
\end{tabular}

RA Rheumatoid arthritis, SS Sjogrensyndrome, SLE Systemic lupus erythematosus, IIM Idiopathic inflammatory myopathy, SSC Systemic sclerosis, MCTD Mixed connective tissue disease, OS Overlap syndrome, CTD Connective tissue disease, CTD-ILD Interstitial lung disease associated with connective tissue disease 
Table 4 The serum KL-6 level from the four different groups of patients

\begin{tabular}{lll}
\hline Groups & $\begin{array}{l}\text { KL-6 level (IU/ml) } \\
\text { Median (IQR) }\end{array}$ & $p$ \\
\hline CTD-ILD & $1004.9(676.41738 .1)$ & $<0.001^{a}$ \\
CTD & $468.0(272.61005 .9)$ & $<0.001^{b}$ \\
Pulmonary infection & $526.4(439.7,670.0)$ & $<0.001^{c}$ \\
Normal & $452.5(338.3,550.0)$ & $<0.001^{d}$ \\
\hline
\end{tabular}

CTD Connective tissue disease, CTD-ILD Interstitial lung disease associated with connective tissue disease. Note: ${ }^{a}$ comparing among 4 groups; ${ }^{\text {b-d }}$ each compared to CTD-ILD group

patients had idiopathic inflammatory myopathy (16.13\%), 26 patients had systemic sclerosis $(16.77 \%), 7$ patients had mixed connective tissue disease (4.52\%), 3 patients had overlap syndrome (1.94\%), and 10 patients had vasculitis (6.45\%). Finally, the overall incidence of ILD was $54.19 \%$ (Table 3).

In the CTD-ILD group, all patients had received HRCT scanning and 67 patients had received pulmonary function test (PFT). Also, 5 patients did not meet the criteria for PFT due to critical illness, and 12 patients refused to accept the inspection.

\section{The serum KL-6 level varies in different groups}

The serum KL-6 level in CTD-ILD group (medium level, $1004.95 \mathrm{IU} / \mathrm{ml}$ ) was higher than CTD group (medium level, $467.99 \mathrm{IU} / \mathrm{ml})$. We also found that the serum KL-6 level in CTD-ILD patients was significantly higher than those in patients with pulmonary infection and normal physical examination group (Table 4).

\section{Correlations between the serum KL- 6 level and the severity of CTD-ILD disease}

The HRCT scanning and DLCo are used to evaluate the extent and severity of CTD-ILD disease. The higher HRCT scores indicate the wider extent of CTD-ILD affected tissues, while the lower DLCo scores indicate the more severe CTD-ILD disease states. The level of serum KL-6 was positively correlated with HRCT scores $(r=0.75, P<0.001)$, and was negatively correlated with DLCo $(r=-0.50, P<0.001)$ (Figs. 1 and 2$)$, suggesting that serum KL-6 levels may be used as an auxiliary indicator for HRCT and DLCo for patient assessment.

\section{The serum KL- 6 level correlates with the prognosis after CTX treatment}

After received CTX pulse therapy, all 32 patients received HRCT scanning and PFT at three time points to assess the effectiveness of their treatment. Overall there were 20 patients diagnosed as remission, and the rest of 12 patients were classified as non-remission. Within those 20 patients with disease remission diagnosis, their serum KL-6 levels gradually decreased over time (Fig. 3). However, high serum level of KL-6 persisted ( $>1000$ IU/ $\mathrm{ml}$ ) at all time points among non-remitters, even though whose disease condition did improve to some extents after treatment compared to pre-treatment (Fig. 4).

The effectiveness of using serum KL- 6 level measurement as a risk factor for ILD occurrence

Using logistic multivariate regression, we showed that among several patient characteristics, high serum KL-6

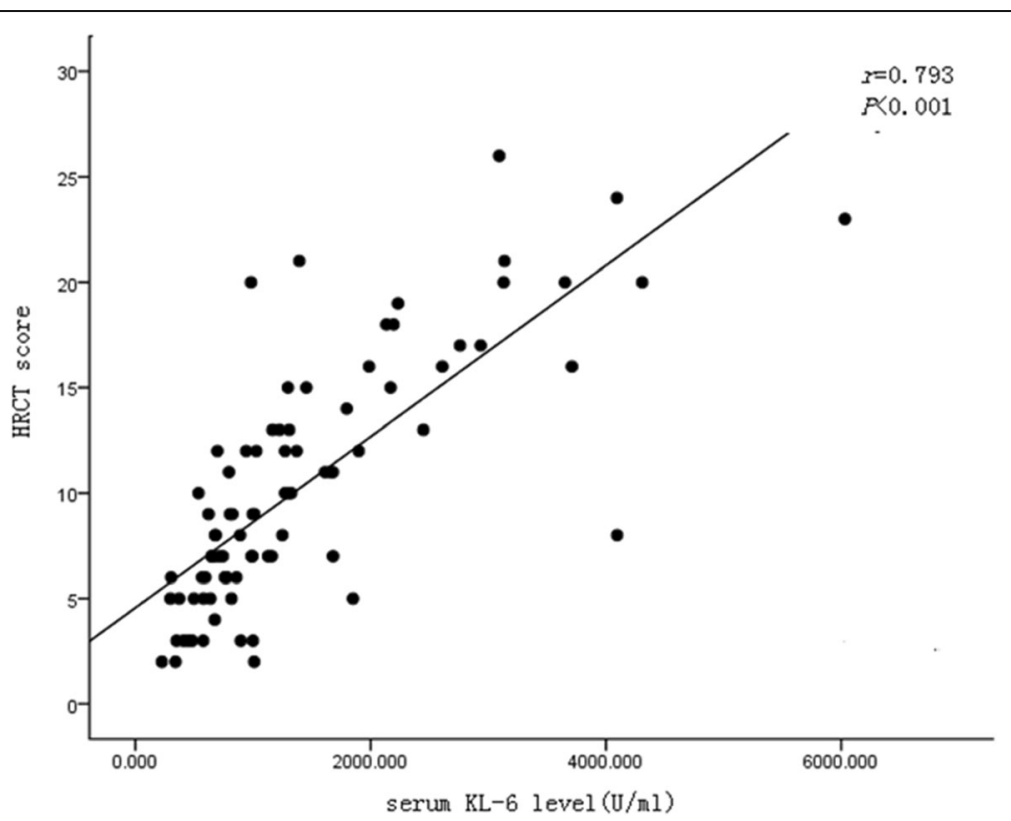

Fig. 1 The correlation between serum KL-6 level and HRCT scores. The level of serum KL-6 was positively correlated with HRCT scores $(r=0.75, P<0.001)$ 


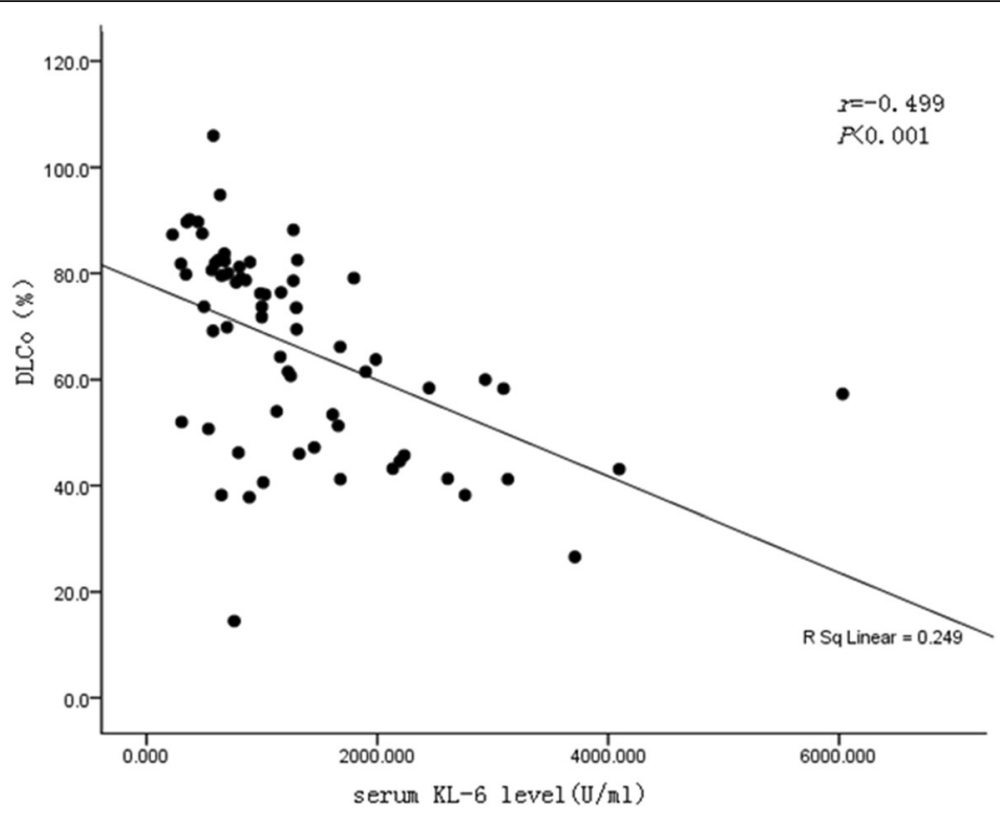

Fig. 2 The relationship between serum KL-6 levels and DLCo. The level of serum KL-6 was negatively correlated with DLCo $(r=-0.50, P<0.001)$

level and Raynaud's phenomenon served as good indicators for the onset of CTD-ILD (Table 5). Upon further analysis, we showed that the area under the curve (AUC) of the receiver operating characteristic (ROC) curve from KL-6 is 0.76, higher than 0.69 from Raynaud's phenomenon (Table 6 and Fig. 5), which suggested the serum KL-6 level indeed has a decent, if not better, predicting value as a risk factor for ILD occurrence.

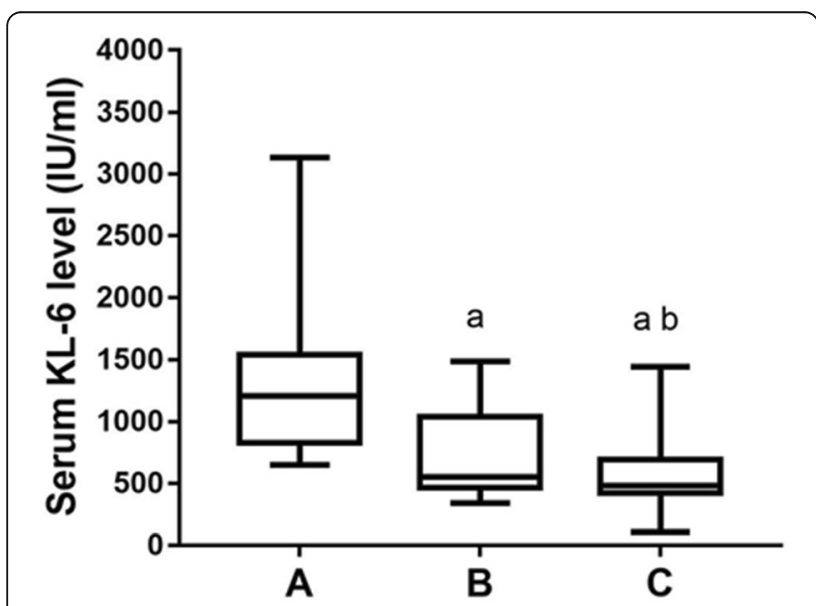

Fig. 3 The changes of serum KL-6 level in 20 patients with improved condition after CTX therapy. The serum KL-6 levels gradually decreased over time in the patients with disease remission diagnosis. A: before treatment, B: 3 months after treatment, C: 6 months after treatment. a, compared with before treatment $p<0.05 ; \mathrm{b}$, compared with 3 months after treatment $p<0.05$

\section{Discussion}

The ILD is an important manifestation of visceral involvement in patients with CTD, and often diagnosed at an advanced stage. About 15\% of patients are affected with both CTD and ILD [16]. The CTD-ILD, which is caused by autoimmune responses in the alveolar epithelium with different degrees of inflammation and fibrosis. Early manifestations of CTD-ILD are exudative alveolitis, widely deposited late collagen fibers, resulting in irreversible changes in pulmonary fibrosis and pulmonary dysfunction [17]. The decline of lung function caused by the CTD-ILD directly leads to increased mortality in patients and impacts the prognosis of patients [18]. At present, CTD-ILD diagnosis mainly depends on HRCT and pulmonary function test, but these tests have some inherent limitations such as high cost, poor reproducibility, as well as the incompatibility for critically ill patients.

The KL-6 is a glycoprotein antigen expressed on alveolar type II epithelial cells and bronchial epithelial cells, belonging to the $\mathrm{MUCl}$ family [8]. Damaged alveolar epithelial cells release large amount of KL-6, which then can cause fibroblast aggregation and the inhibition of fibroblast apoptosis. When alveoli injured, the blood exchange barrier permeability increased, and the KL-6 swarm into the blood, which resulted in increased serum KL-6 level [19]. Given that the KL-6 is not an alveolar surfactant, over production of KL-6 may affect the expression of the original surfactant, alveolar expansion and then damage lung compliance, leading to ventilation dysfunction and long-term lung injury [20]. Therefore, the serum KL-6 level has been considered as a marker to predict the onset of ILD [21]. 


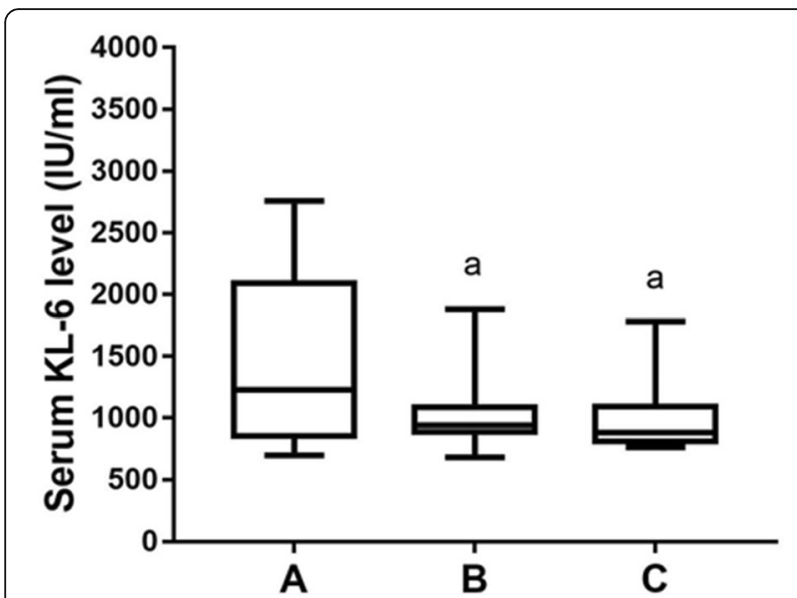

Fig. 4 The changes of serum KL- 6 level in 12 patients after CTX therapy. The serum level of KL- 6 showed no significant changes between 3 months and 6 months after treatment in non-responsive patients. A: before treatment, B: 3 months after treatment, C: 6 months after treatment. a, compared with before treatment $p<0.05$

In our study, we found that the serum KL-6 level in CTD-ILD patients was significantly higher than all other groups, suggesting that the increased serum KL-6 level may indeed indicate the occurrence of ILD. Interestingly, there were a few patients presented high serum KL-6 level without obvious clinical symptoms or detectable pathological image by HRCT. It is possible that the alveolar structures of these patients sustained some damages, but not to a degree showing clinical and imaging manifestations, so future follow-ups will be required to discern if these patients will progress to ILD in the future, which can help us to further evaluate whether serum KL-6 level can be used to predict the onset of CTD-ILD before the appearance of clinical symptoms or any detectable changes by imaging exams.
The long-term use of corticosteroids and immunosuppressive agents in CTD patients increases the risk of pulmonary infection, which is a major cause of the mortality. Meanwhile, the rapid progression of CTD-ILD is often triggered by infection; so early identification of cough symptoms or lung infection caused by CTD-ILD is critical for guiding clinical treatment [22]. It has been shown that the level of serum KL-6 can be used to identify SLE (systemic lupus erythematosus) lung infection and SLE-ILD [23]. Interestingly, our study found that the level of serum KL-6 in patients with CTD-ILD is even higher than that of pulmonary infection, which would require further analyses to better understand its diagnostic value. Previous literatures reported that the level of serum KL-6 was significantly increased in patients with Pneumocystis carinii infection and showed no significant difference when compared with CTD-ILD patients. Because it is difficult to distinguish Pneumocystis carinii infection and ILD on HRCT alone, we should seek other etiological evidence in the clinic to help making accurate diagnosis and treatment [24].

As for CTD-ILD patients, the CTX treatment plays a crucial role in their prognosis and is the only immunosuppressive agents proven by randomized controlled study that can effectively stabilize the patient's lung function. Previous studies have suggested that the serum KL- 6 levels can be used to evaluate the effectiveness of CTX pulse therapy for SSc-ILD patients $[11,15]$. Consistently, data from our study showed that the level of serum KL-6 in CTD-ILD patients with improved condition after CTX treatment was significantly reduced (Figs. 3 and 4). Therefore, we believe that the changes in serum KL-6 levels may be used to assess the therapeutic effect of CTX pulse therapy in the CTD-ILD patients and their following prognosis. However, due to the low AUC of the ROC curve, it is prudent to use the measured KL- 6 value as one of the indicators, preferably in

Table 5 The risk factors for CTD-ILD occurrence

\begin{tabular}{|c|c|c|c|c|c|c|c|}
\hline \multirow[t]{2}{*}{ Model } & \multirow[t]{2}{*}{ Variables } & \multirow{2}{*}{$\begin{array}{l}\text { Risk } \\
\text { Factor }\end{array}$} & \multirow[t]{2}{*}{ Parameter } & \multirow[t]{2}{*}{ OR } & \multicolumn{2}{|c|}{$95 \% \mathrm{Cl}$ of $\mathrm{OR}$} & \multirow[t]{2}{*}{$p$} \\
\hline & & & & & Lower & Upper & \\
\hline \multirow[t]{7}{*}{ Model $1^{a}$} & & & -1.24 & - & - & - & - \\
\hline & $\mathrm{KL}-6$ & Unit $=100$ & 0.141 & 1.151 & 1.069 & 1.240 & $<0.001$ \\
\hline & LDH & Unit $=20$ & 0.001 & 1.001 & 0.990 & 1.013 & 0.826 \\
\hline & $\lg G$ & Unit $=1$ & 0.037 & 1.038 & 0.977 & 1.102 & 0.226 \\
\hline & Raynaud's phenomenon & Yes VS. No & 1.162 & 10.226 & 3.197 & 32.712 & $<0.001$ \\
\hline & Arthritis & Yes VS. No & -.317 & 0.531 & 0.234 & 1.207 & 0.131 \\
\hline & ANA & Yes VS. No & 0.234 & 1.597 & 0.642 & 3.970 & 0.314 \\
\hline \multirow[t]{3}{*}{ Model $2^{b}$} & & & -.315 & & & & \\
\hline & $\mathrm{KL}-6$ & Unit $=100$ & 0.129 & 1.138 & 1.063 & 1.219 & $<0.001$ \\
\hline & Raynaud's phenomenon & Yes VS. No & 1.224 & 11.573 & 3.716 & 36.040 & $<0.001$ \\
\hline
\end{tabular}

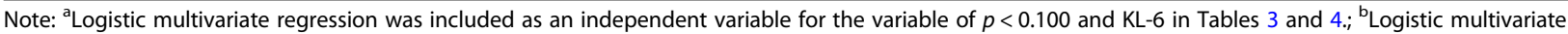
regression using KL-6 and Raynaud's phenomenon as independent variables 
Table 6 The predicting values of CTD-ILD occurrence from KL-6 and Raynaud's phenomenon

\begin{tabular}{|c|c|c|c|c|c|c|c|c|}
\hline \multirow[t]{2}{*}{ Source } & \multirow{2}{*}{$\begin{array}{l}\text { AUC } \\
\text { of } \\
\text { ROC }\end{array}$} & \multicolumn{2}{|c|}{$95 \% \mathrm{Cl}$ of $\mathrm{AUC}$} & \multirow[t]{2}{*}{ Sensitivity } & \multirow[t]{2}{*}{ Specificity } & \multirow{2}{*}{$\begin{array}{l}\text { Positive } \\
\text { predictive } \\
\text { values }\end{array}$} & \multirow{2}{*}{$\begin{array}{l}\text { Negative } \\
\text { predictive } \\
\text { values }\end{array}$} & \multirow{2}{*}{$\begin{array}{l}\text { Cut- } \\
\text { off } \\
\text { valve }\end{array}$} \\
\hline & & Lower & Upper & & & & & \\
\hline KL-6 & 0.762 & 0.687 & 0.838 & 0.821 & 0.620 & 0.684 & 0.776 & 617 \\
\hline Raynaud's phenomenon & 0.698 & 0.638 & 0.758 & 0.452 & 0.944 & 0.890 & 0.633 & - \\
\hline
\end{tabular}

combination with other existing biomarkers for the clinical evaluation on treatment effectiveness (Fig. 5).

Indeed, some limitations on the result interpretation existed in our study. For instance, we did not consider the effects of smoking and other possible confounding factors during our study, including age, gender, races, patient occupations and living condition/environments, due to the lack of access to larger sample sets from multiple geological locations, given the limited resource we currently have. In addition, with the small size of patient sample we collected and analyzed, as well as the heterogeneous nature of CTD-ILD diseases (which was inadvertently included due to limited patient recruitment period), it would be prudent to view our results as pilot data since several possible confounding factors, including distinct types of CTD, could affect or bias the result interpretation.

\section{Conclusions}

From our analysis, we believe that the elevated serum KL-6 level should be suitable to be used to support the diagnosis of CTD-ILD disease, or at least as an auxiliary indicator. In addition, the reduction of serum KL-6 level after CTX pulse therapy presents itself as a supporting

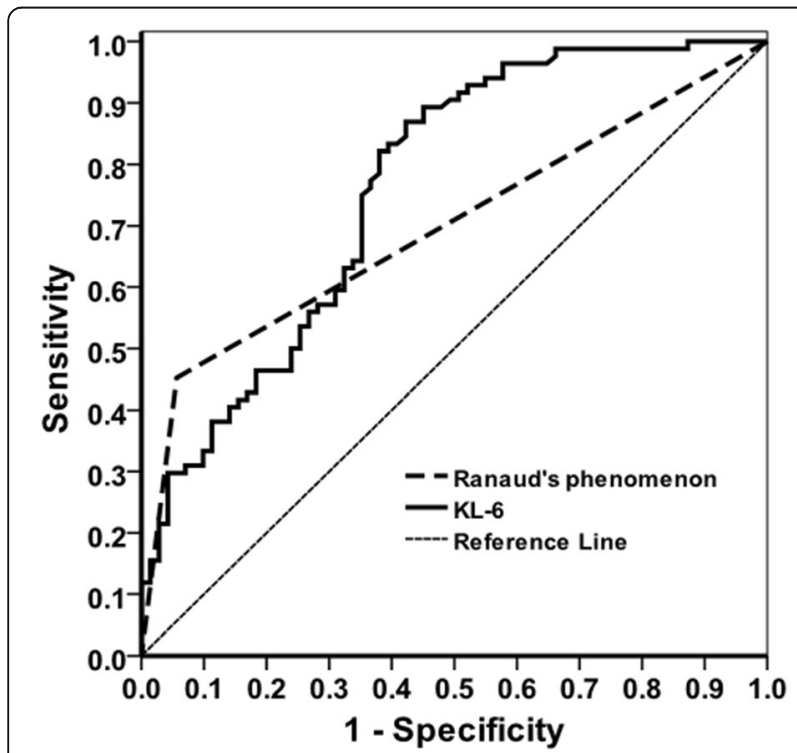

Fig. 5 The ROC curve for serum KL-6 level for usefulness evaluation. The area under the curve is 0.81 . When the cut-off value is set to $617.73 \mathrm{IU} / \mathrm{ml}$, sensitivity $(0.82)$ and specificity $(0.72)$ reach the maximum, which is the best working point indicator for treatment effectiveness in the CTD-ILD patients in combination with other diagnostic biomarkers. Finally, even though our study was limited in scale, we remain confident that serum level of KL-6 could be a promising biomarker for the severity of interstitial lung disease in the future, which would undoubtedly depend on more detailed and comprehensive further studies to address confounding variables first.

\section{Abbreviations}

CTD: Connective tissue diseases; CTX: Cyclophosphamide; DLCo: Carbon monoxide diffusing capacity; ELISA: Enzyme linked immunosorbent assay; HRCT: High-resolution computed tomography; KL-6: Serum krebs von den lungen-6; PFT: Pulmonary function test; SSc: Systemic sclerosis

\section{Acknowledgements}

None declared.

\section{Authors' contributions}

SY contributed to the study design, HM and JL performed the data analysis, YS and HW prepared the manuscript, all the authors made the final approval.

\section{Funding}

This study was supported by Science and Technology Project of Xuzhou city (KC16SH111). The funder gave economical support to the study, but was not involved in in the design of the study, the collection of data, analysis,

interpretation of data or in writing the manuscript.

\section{Availability of data and materials}

The datasets supporting the conclusions of this article are included within the article.

\section{Ethics approval and consent to participate}

The study protocol was approved by the Ethic Committee of the Affiliated Hospital of Xuzhou Medical University and conducted in accordance with

Helsinki's Declaration. All the patients gave their written information consent.

Consent for publication

Not applicable.

Competing interests

The authors declare that they have no competing interests.

\section{Author details}

'Department of Rheumatology and Immunology, Affiliated Hospital of Xuzhou Medical University, No. 99 Huaihai West Road, Xuzhou 221002, China. ${ }^{2}$ Department of Rheumatology and Immunology, Huai'an Second People's Hospital, Huai'an 223002, China.

Received: 8 April 2019 Accepted: 26 December 2019

Published online: 08 January 2020

\section{References}

1. Rao V, Bowman S. Latest advances in connective tissue disorders. Ther Adv Musculoskelet Dis. 2013;5(4):234-49.

2. Hoffmann AM, Vold AM, Aaløkken TM, Lund MB, et al. Predictive value of serial high-resolution computed tomography analyses and concurrent lung function tests in systemic sclerosis. Arthritis Rheumatol. 2015;67(8):2205. 
3. Saketkoo LA, Matteson EL, Brown KK, et al. Developing disease activity and response criteria in connective tissue disease-related interstitial lung disease. J Rheumatol. 2011;38(7):1514-8.

4. Afeltra A, Zennaro D, Garzia P, Gigante A, Vadacca M, Ruggiero A, Dardes N, Navajas MF, Zobel BB, Amoroso A. Prevalence of interstitial lung involvement in patients with connective tissue diseases assessed with highresolution computed tomography. Scand J Rheumatol. 2006;35(5):388-94.

5. Lee HN, Kim MY, Koo HJ, et al. Thin-section CT characteristics and longitudinal CT follow-up of chemotherapy induced interstitial pneumonitis: a retrospective cohort study. Medicine. 2016;95(2):e2460.

6. Skolnik K, Ryerson CJ. Unclassifiable interstitial lung disease: a review. Respirology. 2016;21(1):51-6.

7. Bonella $\mathrm{F}$, Costabel U. Biomarkers in connective tissue disease-associated interstitial lung disease. Semin Respir Crit Care Med. 2014;35(2):181.

8. Kohno N, Akiyama M, Kyoizumi S, et al. Detection of soluble tumorassociated antigens in sera and effusions using novel monoclonal antibodies, KL-3 and KL-6, against lung adenocarcinoma. Jpn J Clin Oncol. 1988;18(3):203

9. Inoue $Y$, Barker E, Daniloff E, et al. Pulmonary epithelial cell injury and alveolar-capillary permeability in berylliosis. Am J Respir Crit Care Med. 1997; 156(1):109.

10. Kobayashi N, Takezaki S, Kobayashi I, et al. Clinical and laboratory features of fatal rapidly progressive interstitial lung disease associated with juvenile dermatomyositis. Rheumatology. 2015;54(5):784.

11. Kuwana M, Shirai Y, Takeuchi T. Elevated serum krebs von den lungen-6 in early disease predicts subsequent deterioration of pulmonary function in patients with systemic sclerosis and interstitial lung disease. J Rheumatol. 2016:43(10):1825-31.

12. Yamakawa $\mathrm{H}$, Hagiwara $\mathrm{E}$, Kitamura $\mathrm{H}$, et al. Clinical features of idiopathic interstitial pneumonia with systemic sclerosis-related autoantibody in comparison with interstitial pneumonia with systemic sclerosis. PLoS One. 2016;11(8):e0161908.

13. Yamakawa H, Hagiwara E, Kitamura H, et al. Serum KL-6 and surfactant protein-D as monitoring and predictive markers of interstitial lung disease in patients with systemic sclerosis and mixed connective tissue disease. J Thorac Dis. 2017:9(2):362.

14. Gotway MB, Reddy GP, Webb WR, et al. High-resolution CT of the lung: patterns of disease and differential diagnoses. Radiol Clin North Am. 2005; 43(3):513.

15. Saigusa R, Asano Y, Nakamura $K$, et al. Plasma plasmin-a2-plasmin inhibitor complex levels may predict the effect of cyclophosphamide for systemic sclerosis-related interstitial lung disease. Mod Rheumatol. 2017;27(4):618-22.

16. Sharp C, Dodds N, Mayers $L$, et al. The role of biologics in treatment of connective tissue disease-associated interstitial lung disease. Qjm. 2015; 108(9):74-80.

17. Strange $C$, Highland KB. Interstitial lung disease in the patient who has connective tissue disease. Clin Chest Med. 2004;25(3):549.

18. Dellaripa PF. Interstitial lung disease in the connective tissue diseases; a paradigm shift in diagnosis and treatment. Clin Immunol. 2018;186:71-73.

19. Huang G, Brigstock DR. Regulation of hepatic stellate cells by connective tissue growth factor. Front Biosci. 2012;17(17):2495.

20. Hesselstrand R, Wildt M, Bozovic G, et al. Biomarkers from bronchoalveolar lavage fluid in systemic sclerosis patients with interstitial lung disease relate to severity of lung fibrosis. Respir Med. 2013;107(7):1079-86.

21. Chen F, Lu X, Shu X, et al. Predictive value of serum markers for the development of interstitial lung disease in patients with polymyositis and dermatomyositis: a comparative and prospective study. Intern Med J. 2015 45(6):641-7.

22. Song JW, Hong S, Lim C, et al. Acute exacerbation of idiopathic pulmonan fibrosis: incidence, risk factors and outcome. Eur Respir J. 2011;37(2):356-63.

23. Ogawa N, Shimoyama K, Kawabata $H$, et al. Clinical significance of serum KL-6 and SP-D for the diagnosis and treatment of interstitial lung disease in patients with diffuse connective tissue disorders. Ryūmachi [Rheumatism]. 2003;43(1):19-28

24. Tasaka S, Hasegawa N, Yamada W, et al. Clinical features of Pneumocystis pneumonia in patients with systemic lupus erythematosus. Nihon Kokyuki Gakkai Zasshi. 2006;44(9):613-9

\section{Publisher's Note}

Springer Nature remains neutral with regard to jurisdictional claims in published maps and institutional affiliations.

Ready to submit your research? Choose BMC and benefit from:

- fast, convenient online submission

- thorough peer review by experienced researchers in your field

- rapid publication on acceptance

- support for research data, including large and complex data types

- gold Open Access which fosters wider collaboration and increased citations

- maximum visibility for your research: over $100 \mathrm{M}$ website views per year

At $\mathrm{BMC}$, research is always in progress.

Learn more biomedcentral.com/submissions 